though the total number of perinatal deaths in this group is small.

\section{Neonatal Intensive Care}

- There were 1,899 infants registered in the Neonatal Intensive Care Units' Data Collection in 1998 representing a registration rate of 21.0 per 1,000 live births.

- The proportion of women receiving antenatal corticosteroids for fetal lung maturation has increased each year since 1992, with 70.2 per cent of mothers receiving steroids in 1998.

- Most infants (82.5 per cent) were from a singleton pregnancy, 16.0 per cent were from a twin pregnancy and 1.3 per cent were from a triplet pregnancy.

- During 1998, 74.4 per cent of infants registered were preterm (less than 37 weeks gestation), 46.1 per cent were very preterm (less than 32 weeks) and 15.1 per cent were extremely preterm (less than 28 weeks). One in six infants had a major or minor congenital anomaly.

- The majority of infants registered in 1998 (89.9 per cent) received assisted ventilation. The main indication for assisted ventilation varied with gestational age: respiratory distress syndrome, immature lung and transient tachypnoea were more common among the preterm groups, whereas meconium aspiration, perinatal asphyxia and pulmonary hypertension were more common in term infants.

- Overall, 92.5 per cent of infants without a major congenital anomaly survived to six months of age.
Survival improved with gestational age up to 34 weeks, after which it decreased slightly.

\section{Birth defects}

- About 2,000 infants are born with birth defects each year in NSW. Over the period 1992-98, defects of the cardiovascular system were most commonly reported, followed by defects of the musculoskeletal system and defects of the genito-urinary system. The number of infants born with neural tube defects slowly decreased from 80 in 1992 to 51 in 1997.

- The rate of birth defects increases with increasing maternal age, especially after age 35 . However, as most babies are born to mothers aged less than 35 years, the majority of babies with birth defects were born to younger mothers.

\section{Clinical indicators for obstetrics}

- From 1st January 1998, the MDC includes data elements necessary for most of the Australian Council on Healthcare Standards and Royal Australian and New Zealand College of Obstetricians and Gynaecologists (ACHS-RANZCOG) clinical indicators for obstetrics. A summary of the indicators for all NSW hospitals combined and comparative information for participating Australian hospitals are shown in Table 1. Fit

The New South Wales Mothers and Babies Report, 1998 is available from the NSW Department of Health's Web site at www.health.nsw.gov.au/ public-health/mdc/mdcrep98.html.

\title{
REPORTING ON INDIGENOUS HEALTH: REPORT OF THE CHIEF HEALTH OFFICER, 2000
}

\section{Peter Waples and Louisa Jorm}

Epidemiology and Surveillance Branch

NSW Department of Health

\section{INTRODUCTION}

The NSW Department of Health has recently released an updated version of the Health of the people of NSW: Report of the Chief Health Officer, 2000. This report, last published in 1997, is a key mechanism for communicating population health information in NSW. It provides a detailed account of the available measures of health for the residents of NSW, including Aboriginal and Torres Strait Islander peoples. The chapter on indigenous health in the 2000 report was substantially revised and expanded following an evaluation of its 1997 counterpart. This article gives an overview of the evaluation process and the subsequent revision of the chapter.

\section{METHODS}

A one-page fax-back questionnaire was developed, seeking comments on the content, layout, and usefulness of the chapter on indigenous health in the 1997 Report of the Chief Health Officer. This chapter covered the following topics:

- projected indigenous population 
- perinatal deaths

- premature births

- recording of indigenous status

- premature mortality

- hospitalisation

- indigenous population pyramid

- diabetes mellitus

- respiratory disease

- cardiovascular risk factors

- injury and poisoning

- vaccine-preventable diseases

- alcohol consumption

- cardiovascular disease.

In mid-March 1999, the questionnaire was electronically mailed or faxed to relevant staff in the NSW Department of Health, Directors of NSW Public Health Units, Chief Executive officers of Aboriginal Medical Services, and Aboriginal Health Coordinators. A total of 90 questionnaires were distributed.

\section{RESULTS}

Thirty-four questionnaires were returned, giving a response rate of 38 per cent. Of the 34 respondents, 14 (41 per cent) were Aboriginal.

Thirty respondents ( 88 per cent) had read or used the report, three had not read the report, and one was not sure whether or not they had read the report.

Twenty-six respondents (76 per cent) suggested new topics to be included in the chapter, with the most often cited being:

- environmental health

- mental health

- socioeconomic factors and health

- sexual health

- oral health

- drug use and other risk behaviours.

Twelve respondents ( 35 per cent) thought that indigenous health issues should be presented mainly in a discrete chapter. Twenty (59 per cent) preferred a discrete chapter combined with comparisons with other populations spread throughout the report. No respondents supported dropping the special chapter on indigenous health, though two respondents (five per cent) voiced no preference on this issue.

Two important themes that emerged from respondents' comments were:

- The need to avoid stigmatising Aboriginal communities when presenting information on sensitive subjects (such as sexual health, mental health and drug use, and other risk behaviours), particularly at Area Health Service level.

- The potential reinforcement of negative stereotypes by presenting information on the relatively poor health status of Aboriginal people. Some respondents suggested that the report should highlight any recent improvements in indigenous health or its determinants.

\section{DISCUSSION}

The results of the evaluation supported the retention and expansion of a designated chapter on indigenous health in the Report of the NSW Chief Health Officer, 2000. However, addition of new material to the report, in line with the suggestions made in the evaluation, was severely constrained by the limitations of the available data. In NSW, Aboriginality is often poorly recorded in relevant data collections, and as a consequence, there are limited sources of routinely collected data.

However, new information on the following topics is included in the 2000 report:

- socioeconomic factors (using 1996 census data)

- health-related behaviours (using data from the 1997 and 1998 NSW Health Surveys)

- renal dialysis (using NSW Inpatients Statistics Collection data, internally linked to remove duplicate records for individuals)

- psychosocial distress (using data from the 1997 and 1998 NSW Health Surveys).

In addition, the new report contains:

- more internet references to link readers to appropriate Aboriginal and Torres Strait Islander health sites throughout Australia;

- wherever possible throughout the report, comparative statistics to highlight health disparities between indigenous and non-indigenous people.

A statewide project to improve the recording of Aboriginality in health care settings is currently being undertaken as part of the NSW Aboriginal Health Information Strategy. Encouragingly, registrations of indigenous deaths in NSW improved in 1998 compared with previous years. It is hoped that further improvements in the scope and quality of the available data will allow the issues raised in this evaluation to be more fully addressed in subsequent editions of the Chief Health Officer's Report.

\section{ACKNOWLEDGEMENT}

We would like to thank those who gave their time to participate in the evaluation. 